\title{
From the chlorophyll $a$ in the surface layer to its vertical profile: a Greenland Sea relationship for satellite applications
}

\author{
A. Cherkasheva ${ }^{1,2}$, E.-M. Nöthig ${ }^{1}$, E. Bauerfeind ${ }^{1}$, C. Melsheimer ${ }^{2}$, and A. Bracher ${ }^{1,2}$ \\ ${ }^{1}$ Alfred Wegener Institute for Polar and Marine Research, Bremerhaven, Germany \\ ${ }^{2}$ Institute of Environmental Physics, University of Bremen, Bremen, Germany
}

Correspondence to: A. Cherkasheva (acherkasheva@uni-bremen.de)

Received: 14 September 2012 - Published in Ocean Sci. Discuss.: 15 November 2012

Revised: 4 March 2013 - Accepted: 15 March 2013 - Published: 9 April 2013

\begin{abstract}
Current estimates of global marine primary production range over a factor of two. Improving these estimates requires an accurate knowledge of the chlorophyll vertical profiles, since they are the basis for most primary production models. At high latitudes, the uncertainty in primary production estimates is larger than globally, because here phytoplankton absorption shows specific characteristics due to the low-light adaptation, and in situ data and ocean colour observations are scarce. To date, studies describing the typical chlorophyll profile based on the chlorophyll in the surface layer have not included the Arctic region, or, if it was included, the dependence of the profile shape on surface concentration was neglected. The goal of our study was to derive and describe the typical Greenland Sea chlorophyll profiles, categorized according to the chlorophyll concentration in the surface layer and further monthly resolved profiles. The Greenland Sea was chosen because it is known to be one of the most productive regions of the Arctic and is among the regions in the Arctic where most chlorophyll field data are available. Our database contained 1199 chlorophyll profiles from R/Vs Polarstern and Maria S. Merian cruises combined with data from the ARCSS-PP database (Arctic primary production in situ database) for the years 1957-2010. The profiles were categorized according to their mean concentration in the surface layer, and then monthly median profiles within each category were calculated. The category with the surface layer chlorophyll (CHL) exceeding $0.7 \mathrm{mg} \mathrm{C} \mathrm{m}^{-3}$ showed values gradually decreasing from April to August. A similar seasonal pattern was observed when monthly profiles were averaged over all the surface CHL concentrations. The maxima of all chlorophyll profiles moved from the greater depths to the surface from spring to late summer respectively.
\end{abstract}

The profiles with the smallest surface values always showed a subsurface chlorophyll maximum with its median magnitude reaching up to three times the surface concentration. While the variability of the Greenland Sea season in April, May and June followed the global non-monthly resolved relationship of the chlorophyll profile to surface chlorophyll concentrations described by the model of Morel and Berthon (1989), it deviated significantly from the model in the other months (July-September), when the maxima of the chlorophyll are at quite different depths. The Greenland Sea dimensionless monthly median profiles intersected roughly at one common depth within each category. By applying a Gaussian fit with $0.1 \mathrm{mg} \mathrm{C} \mathrm{m}^{-3}$ surface chlorophyll steps to the median monthly resolved chlorophyll profiles of the defined categories, mathematical approximations were determined. They generally reproduce the magnitude and position of the CHL maximum, resulting in an average $4 \%$ underestimation in $C_{\text {tot }}$ (and $2 \%$ in rough primary production estimates) when compared to in situ estimates. These mathematical approximations can be used as the input to the satellite-based primary production models that estimate primary production in the Arctic regions.

\section{Introduction}

The current uncertainty in the global marine primary production (PP) estimates is high, with values ranging over a factor of two (Carr et al., 2006). The most challenging regions for PP modelling are poleward of $40^{\circ}$ in all basins (Carr et al., 2006), where the range of PP estimates is even higher. In the Arctic Ocean the uncertainties are mainly caused by the 
unique optical properties of the Arctic waters and the presence of a subsurface chlorophyll maximum (SCM) (Arrigo et al., 2011; Weston et al., 2005; Matsuoka et al., 2007, 2011). The SCM is often not correctly seen by the satellite as it lies below the surface layer visible to the satellite sensor. To include the information on the SCM into primary production models accurately, one needs to find the appropriate relationship between the chlorophyll (CHL) concentration in the surface layer and its vertical profile. There have been a number of methods developed to handle this. The PP model by Behrenfeld and Falkowski (1997) considers the CHL profile to be uniform throughout the water column. The model by Antoine and Morel (1996) and Antoine et al. (1996) goes further by assuming that the CHL profile changes its shape according to the concentration of the surface layer. On the contrary, the recent Arctic PP model by Arrigo et al. (2011) adopts a fixed shape of CHL profile for a specific month and region.

In this study, though being generally interested in the Arctic primary production, we focus on the Greenland Sea for several reasons: firstly, the Greenland Sea is known to be one of the most productive regions of the Arctic (Reigstad, 2011; Sakshaug, 2004; Arrigo and Van Dyiken, 2011). Secondly, it is one of the few areas in the world where deep convective mixing occurs, possibly transferring significant amounts of carbon dioxide to great depths (Rey et al., 2000). Finally, it is one of the regions in the Arctic where the most in situ CHL data are available (Arrigo et al., 2011). The Greenland Sea was and is in the focus of the hydrographic studies of the Alfred Wegener Institute (AWI), and transects across the Fram Strait have been run repeatedly for many years (e.g. Budeus and Ronski, 2009; Schauer et al., 2008). During these cruises measurements of in situ CHL were carried out regularly. In this study, CHL data from R/Vs Polarstern and Maria $S$. Merian 1991-2010 cruises were combined with data from the Arctic primary production database ARCSS-PP (Matrai et al., 2013; Hill et al., 2013).

The Greenland Sea is a highly dynamic area in terms of water mass exchange, where warmer surface waters of relatively high salinity advected to the area from the North Atlantic meet fresher and colder waters of Arctic origin (Rudels and Quadfasel, 1991). It is also the area where most of the Arctic drifting sea ice is advected. The complex hydrography and the sea ice drift provide conditions (in terms of nutrients, stratification and presence of sea ice) which differ significantly within the Greenland Sea. This in turn implies that the phytoplankton vertical profiles of the Greenland Sea vary significantly, though having a clear seasonal cycle (Rey et al., 2000). To capture such variability, we combine the methods of Morel and Berthon (1989) and Arrigo et al. (2011), by looking for the relationships that describe (1) the change of the CHL profile depending on its surface concentration, and (2) the seasonal cycle of the CHL profile. Finally, we are also interested in identifying the differences between the
Greenland Sea relationship of this study and the global one of Morel and Berthon (1989).

\section{Methods}

\subsection{Data description}

The borders for the Greenland Sea sector of the Arctic were chosen close to Arrigo et al. (2010): north of the Arctic circle at $66^{\circ} 33^{\prime} 39^{\prime \prime} \mathrm{N}$ and between $45^{\circ} \mathrm{W}$ and $20^{\circ} \mathrm{E}$. We combined the CHL data from R/Vs Polarstern and Maria S. Merian 1991-2010 cruises with the ARCSS-PP database (1957-2003). The data covered the months from April till October.

The samples of R/V Polarstern and Maria S. Merian cruises were collected for 6 depths in Niskin bottles, with 0.5-2.0 L of water filtered through Whatman GF/F glasfibre filter, stored at $-18^{\circ} \mathrm{C}$ and afterwards analysed in the $\mathrm{Al}-$ fred Wegener Institute laboratory. The filters were extracted in $90 \%$ acetone and analysed with a spectrophotometer for higher values and with a Turner-Design fluorimeter for lower values according to the methods described in Edler (1979) and Evans and O'Reily (1987). The values from the fluorimeter were calibrated with the values obtained from the spectrophotometer. In addition, calibration of the fluorimeter was carried out with Sigma chlorophyll $a$ standard. The samples were taken while the ship was underway (surface sampling) and while stationary (vertical profile sampling, henceforth "stations"). In this study we consider only the samples from the stations as we are interested in information on the vertical profile. Refer to Matrai et al. (2013) and Hill et al. (2013) for details on the ARCSS-PP database.

The irradiance profiles were measured with the hyperspectral radiometer (RAMSES, TriOS GmbH, Germany). The instrument had a cosine collector fixed in front of it and covered a wavelength range of 350 to $950 \mathrm{~nm}$ with an optical resolution of $3.3 \mathrm{~nm}$ and a spectral accuracy of $0.3 \mathrm{~nm}$. All the measurements were obtained with an automated integration time of the respective sensor between $4 \mathrm{~ms}$ and $8 \mathrm{~s}$. A reference irradiance device was placed above the water surface to monitor the downwelling incident sunlight and allow the normalization of the in-water measurements according to Stramski et al. (2008). The irradiance profiles were collected simultaneously with the CTD profiles.

\subsection{Data quality control and preprocessing}

The data quality control procedure for the CHL data consisted of filtering out all profiles which either had less than three depths or belonged to the month of October since the number of data points in October was fewer than 20. In cases where several profiles were measured at one location and in one day, we took only the profile with the most sampled depths. If either the location or the day changed, we considered it to be a new profile. Profiles that did not reach the 
surface were extrapolated to the surface as described below. To avoid negative values we put $0.01 \mathrm{mg} \mathrm{C} \mathrm{m}^{-3}$ as the lowest value for the surface. Finally, we gridded the extrapolated profiles to $1 \mathrm{~m}$ increments for further statistical analysis.

By linearly extrapolating the profiles that have a steep change between the two shallowest measurements, additional errors could be introduced. Therefore, we additionally investigated three other ways of handling the difficulty of the majority of profiles that did not reach the surface. These included the following: (1) taking the value of the shallowest depth as the surface CHL; (2) extrapolating only those profiles which changed with a rate less than $0.1 \mathrm{mg} \mathrm{C} \mathrm{m}^{-1}$ between the 2 shallowest measurements and treating other profiles as described in point 1 ; (3) as in point 2 , but with a stricter rate threshold of $0.05 \mathrm{mg} \mathrm{C} \mathrm{m}^{-1}$. Comparing the results of these three different extrapolation methods showed that there was hardly any influence on the shape of the final median profiles. We therefore decided to apply the simple linear extrapolation to the profiles by using the change between the two shallowest measurements.

\subsection{Calculation of the main profiles parameters}

Firstly, the euphotic layer depth $\left(Z_{\mathrm{eu}}\right.$, depth where the downwelling photosynthetically available irradiance is reduced to $1 \%$ of its value at the surface) and CHL integrated for $Z_{\mathrm{eu}}$ $\left(C_{\text {tot }}\right)$ were calculated. Except for nine light profiles taken in 2010, no co-located light measurements for our CHL profile database were available. Thus the euphotic depth was inferred from the CHL profile, using a bio-optical model for light propagation. Following Morel and Berthon (1989), the model of Morel (1988) was used (Eqs. 1a and b) for the estimation of both $Z_{\mathrm{eu}}$ and $C_{\mathrm{tot}}$.

$Z_{\text {eu }}=568.2 C_{\text {tot }}^{-0.746}$

when $Z_{\mathrm{eu}}<102 \mathrm{~m}$.

$Z_{\text {eu }}=200.0 C_{\text {tot }}^{-0.293}$

when $Z_{\text {eu }}>102 \mathrm{~m}$.

To determine the $C_{\text {tot }}$ value, a given profile was progressively integrated with respect to increasing depth $(z)$. The successive integrated CHL values were introduced in Eq. (1a), thus providing successive " $Z_{\mathrm{eu}}$ " values that were progressively decreasing. Once the last " $Z_{\text {eu }}$ " value, as obtained, became lower than the depth $z$ used when integrating the profile, these $C_{\mathrm{tot}}$ and $Z_{\mathrm{eu}}$ values from the last integration were taken. Profiles which did not reach $Z_{\text {eu }}$ were excluded.

The Morel (1988) model for the $Z_{\text {eu }}$ estimation was later revised by Morel and Maritorena (2001), yielding only minor changes in $Z_{\mathrm{eu}}$ (slightly increased $Z_{\mathrm{eu}}$ values in oligotrophic waters, with mean CHL in $Z_{\mathrm{eu}}<0.3 \mathrm{mg} \mathrm{m}^{-3}$ ). As the revised version does not differ appreciably from Morel (1988) for the more productive waters such as Greenland Sea, we used the latter one to be consistent with Morel and Berthon (1989) analysis.
The $Z_{\mathrm{eu}}$ values obtained from nine co-located light and CHL profile measurements from 2010 were used to verify the $Z_{\mathrm{eu}}$ values obtained by the method of Morel and Berthon (1989), $Z_{\mathrm{eu}}^{\mathrm{CHL}}$. In order to calculate $Z_{\mathrm{eu}}$ from the light measurements (here called $Z_{\mathrm{eu}}^{\mathrm{PAR}}$ ), the following method was applied. PAR (photosynthetically active radiation) profiles were obtained by integrating spectrally resolved downwelling irradiance measurements for $400-700 \mathrm{~nm}$. Downwelling irradiance measurements were corrected for incident sunlight following Smith and Baker (1984). To calculate $Z_{\text {eu }}$ from those PAR profiles which did not reach $1 \%$ of the surface PAR value, an exponential function was fitted. The individual profiles are given in the Appendix (Fig. A1). The relative error $(\delta)$ of $Z_{\mathrm{eu}}^{\mathrm{CHL}}$ was computed using the following equation:

$\delta=\left(Z_{\mathrm{eu}}^{\mathrm{CHL}}-Z_{\mathrm{eu}}^{\mathrm{PAR}}\right) / Z_{\mathrm{eu}}^{\mathrm{PAR}}$.

The average value of $\delta$, which equaled $23 \%$, gives us confidence in our determination of the euphotic depth derived from CHL profiles, since it is better than what has been determined in other studies: Milutinovic (2011) estimated $\delta$ values of $24-36 \%$ by comparing global collocated datasets of $Z_{\mathrm{eu}}^{\mathrm{PAR}}$ and $Z_{\mathrm{eu}}^{\mathrm{CHL}}$, with the latter inferred by combining the methods of Morel and Berthon (1989) and Morel and Maritorena (2001). Lee et al. (2007) validated $Z_{\mathrm{eu}}^{\mathrm{CHL}}$ measurements by the $Z_{\mathrm{eu}}^{\mathrm{PAR}}$, using the Morel and Maritorena (2001) model, obtained from data of Monterey Bay, Gulf of Mexico, and the Arabian Sea, resulting in an average error of $33 \%$. Our lower average error than that estimated by Milutinovic (2011) and Lee et al. (2007) is likely to be explained by the low number of light measurements in our database. Generally, some discrepancies between $Z_{\mathrm{eu}}^{\mathrm{CHL}}$ and $Z_{\mathrm{eu}}^{\mathrm{PAR}}$ are to be expected: $Z_{\mathrm{eu}}^{\mathrm{CHL}}$ is determined from a few measurements in the profile, while $Z_{\mathrm{eu}}^{\mathrm{PAR}}$ is determined from continuous measurements. In addition, $Z_{\mathrm{eu}}^{\mathrm{CHL}}$ is based on assuming Case 1 waters, and should differ from $Z_{\mathrm{eu}}^{\mathrm{PAR}}$ in regions with high CDOM (coloured dissolved organic matter) concentrations. Henceforth $Z_{\mathrm{eu}}^{\mathrm{CHL}}$ is referred as $Z_{\mathrm{eu}}$

The penetration depth $\left(Z_{\mathrm{pd}}\right)$, defined according to Gordon and Morel (1983) as the optical depth at which the downwelling irradiance falls to $1 / e$ of its value just below the surface, was obtained as $Z_{\text {eu }}$ divided by $4.6(=\ln 100)$. $Z_{\text {pd }}$ corresponds to the depth of the upper ocean layer where $90 \%$ of optical remote sensing information originates (Gordon and McCluney, 1975). Using $Z_{\mathrm{pd}}$, we calculated the CHL value to be seen by satellite sensor - the mean CHL concentration for the penetration depth layer $\left(C_{\mathrm{pd}}\right)$. Mean $\mathrm{CHL}$ for $Z_{\mathrm{eu}}$ layer $\left(C_{\text {zeu }}\right)$ was computed as well.

The dimensionless profiles (obtained to compare our results to those of Morel and Berthon, 1989) were computed as follows: the dimensionless depth as the actual depth values divided by $Z_{\text {eu }}$ and the dimensionless CHL as the actual CHL values divided by $C_{\text {zeu }}$. Thus the shape of the vertical profiles (for different stations) could be compared regardless of their absolute magnitude (Morel and Berthon, 1989). 


\subsection{Selection of the representative surface layer chlorophyll categories and statistics}

According to the method of Morel and Berthon (1989) and based on a histogram analysis of $C_{\mathrm{pd}}$, we divided all the data into six categories containing an equal number of profiles. Thereafter, we organized the data within each category into monthly bins and calculated the median profiles inside each bin. The median profiles were used in the further analysis as the representative profiles for the certain $C_{\mathrm{pd}}$ in a certain month, because, as opposed to the mean profiles, the median gives less weight to outliers. To have an idea on the spread of the initial data, we plotted half of the interquartile range together with the median.

We additionally calculated the mean, standard deviation, depth of the CHL maximum and its value for each category as they provided a more detailed view on the variation of the data within each category. The $C_{\mathrm{tot}}$ and the ratio of CHL maximum value to $C_{\mathrm{pd}}$ were included to Table 1 to have a further insight into the amount of CHL that is not detected by a satellite sensor. The variability of $C_{\mathrm{tot}} \mathrm{vs} C_{\mathrm{pd}}$ was explored using the White (1980) heteroscedasticity test. With a subset of the data (R/Vs Polarstern and Maria S. Merian 2000-2009 data only), we also investigated the different ways to categorize the profiles (e.g. by latitude, longitude, temperature or salinity of the surface layer). However, the selection of categories based on the CHL in the surface layer and month showed the least variability within a category.

Keeping in mind that we plan to use the results of this study as representative CHL profiles of the Greenland Sea for a certain month and surface concentration which involved the least computational effort, we were interested in having equations to describe the profiles. Thus, we took the processed median profiles and fitted a Gaussian to each of the median profiles in the least squares sense (see Eq. 5). Median profiles were linearly interpolated for surface $\mathrm{CHL}$ values 0 to $5 \mathrm{mg} \mathrm{C} \mathrm{m}^{-3}$ with $0.1 \mathrm{mg} \mathrm{C} \mathrm{m}^{-3}$ steps. The Gaussian shape was chosen for fitting as the vertical profiles of bio-optical profiles such as the chlorophyll maximum layer are shown to be well defined using this shape (Arnone et al., 2007).

\subsection{Analysis of the seasonal variability and reference to uncertainties in primary production estimates}

Monthly CHL profiles of separate $C_{\mathrm{pd}}$ categories can occur in different regions of the Greenland Sea with different nutrient or physical conditions and thus do not always correspond to the seasonal cycle of CHL. In order to account for the contribution of the monthly profiles from the different areas of the Greenland Sea, we firstly averaged all the profiles that were available in our database for each month. In addition, we calculated the monthly profiles for a smaller region to minimize the inhomogeneity of physical conditions. A monthly profile was considered to be valid if it was an average of more than 20 profiles. As a smaller (case study) region,
Table 1. Characteristics of the chlorophyll profiles categorized according to the mean chlorophyll in the surface layer $\left(C_{\mathrm{pd}}\right)$, and then binned into monthly bins. Roman numerals indicate the four ranges of $C_{\mathrm{pd}}\left(\mathrm{mg} \mathrm{C} \mathrm{m}^{-3}\right)$ : (I) $<0.3$; (II) 0.3-0.45; (III) 0.45-0.7; (IV) $>0.7$. $C_{\text {tot }}$ is the total chlorophyll content in the water column, and $Z_{\mathrm{pd}}$ is the penetration depth (also known as the first optical depth). The median, mean, inter-quartile range, and standard deviation are averaged for the whole water column.

\begin{tabular}{|c|c|c|c|c|c|c|c|}
\hline & & Apr & May & Jun & Jul & Aug & Sept \\
\hline \multirow{4}{*}{$\begin{array}{l}\text { Median } \\
\left(\mathrm{mg} \mathrm{Cm}^{-3}\right)\end{array}$} & I & 0.25 & 0.26 & 0.12 & 0.18 & 0.16 & 0.19 \\
\hline & II & 0.61 & 0.31 & 0.30 & 0.26 & 0.30 & 0.19 \\
\hline & III & 0.52 & 0.44 & 0.34 & 0.30 & 0.35 & 0.24 \\
\hline & IV & 1.04 & 0.89 & 0.61 & 0.49 & 0.48 & 0.37 \\
\hline \multirow{4}{*}{$\begin{array}{l}\text { Interquartile } \\
\text { range }(\%)\end{array}$} & I & 75 & 81 & 134 & 62 & 64 & 56 \\
\hline & II & 39 & 47 & 31 & 60 & 54 & 22 \\
\hline & III & 23 & 46 & 25 & 41 & 30 & 24 \\
\hline & IV & 53 & 52 & 46 & 45 & 46 & 27 \\
\hline \multirow{4}{*}{$\begin{array}{l}\text { Depth of CHL } \\
\max (\mathrm{m})\end{array}$} & I & 38 & 37 & 28 & 26 & 25 & 29 \\
\hline & II & 65 & 27 & 23 & 28 & 21 & 8 \\
\hline & III & 1 & 1 & 25 & 16 & 17 & 5 \\
\hline & IV & 2 & 2 & 3 & 11 & 1 & 1 \\
\hline \multirow{4}{*}{$\begin{array}{l}\text { Value of CHL } \\
\max \left(\mathrm{mg} \mathrm{Cm}^{-3}\right)\end{array}$} & I & 0.60 & 0.49 & 0.27 & 0.31 & 0.30 & 0.53 \\
\hline & II & 0.88 & 0.45 & 0.48 & 0.63 & 1.30 & 0.41 \\
\hline & III & 0.59 & 0.60 & 0.65 & 0.68 & 0.90 & 0.62 \\
\hline & IV & 1.95 & 1.61 & 1.32 & 1.28 & 1.47 & 1.19 \\
\hline \multirow{4}{*}{$\begin{array}{l}\text { Mean } \\
\left(\mathrm{mg} \mathrm{C} \mathrm{m}^{-3}\right)\end{array}$} & I & 0.43 & 0.46 & 0.33 & 0.30 & 0.23 & 0.25 \\
\hline & II & 0.68 & 0.42 & 0.41 & 0.42 & 0.35 & 0.20 \\
\hline & III & 0.52 & 0.60 & 0.41 & 0.38 & 0.37 & 0.26 \\
\hline & IV & 1.18 & 1.17 & 0.78 & 0.66 & 0.60 & 0.40 \\
\hline \multirow{4}{*}{$\begin{array}{l}\text { Standard } \\
\text { deviation (\%) }\end{array}$} & I & 102 & 131 & 145 & 116 & 92 & 93 \\
\hline & II & 41 & 80 & 87 & 113 & 58 & 34 \\
\hline & III & 34 & 79 & 68 & 70 & 44 & 33 \\
\hline & IV & 66 & 79 & 72 & 88 & 65 & 42 \\
\hline \multirow{4}{*}{$\begin{array}{l}\text { CHL max/ } \\
C_{\mathrm{pd}}(\%)\end{array}$} & I & 324 & 270 & 176 & 157 & 155 & 292 \\
\hline & II & 207 & 118 & 127 & 169 & 346 & 109 \\
\hline & III & 108 & 108 & 117 & 121 & 157 & 108 \\
\hline & IV & 108 & 92 & 87 & 91 & 89 & 108 \\
\hline \multirow{4}{*}{$\begin{array}{l}C_{\mathrm{tot}} \\
\left(\mathrm{mg} \mathrm{C} \mathrm{m}^{-2}\right)\end{array}$} & I & 22.89 & 22.4 & 16.45 & 20.98 & 19.18 & 19.54 \\
\hline & II & 27.01 & 25.41 & 24.25 & 26.01 & 30.62 & 17.65 \\
\hline & III & 25.89 & 29.32 & 28.51 & 28.16 & 30.59 & 22.71 \\
\hline & IV & 51.88 & 51.34 & 45.16 & 43.06 & 42.92 & 32.26 \\
\hline \multirow{4}{*}{$\begin{array}{l}Z_{\mathrm{pd}} \\
(\mathrm{m})\end{array}$} & I & 19 & 14 & 18 & 15 & 16 & 15 \\
\hline & II & 11 & 12 & 12 & 12 & 11 & 15 \\
\hline & III & 11 & 10 & 10 & 11 & 10 & 12 \\
\hline & IV & 7 & 7 & 8 & 8 & 8 & 10 \\
\hline
\end{tabular}

based on a latitude-longitude density analysis of all samples, the area within $77^{\circ} \mathrm{N}$ to $82^{\circ} \mathrm{N}$ and $5^{\circ} \mathrm{W}$ and $10^{\circ} \mathrm{E}$ was chosen. This is the HAUSGARTEN area, the long-term underwater observatory of the Alfred Wegener Institute (Soltwedel et al., 2005).

In order to roughly assess the effect of the SCM (subsurface chlorophyll maximum) on PP estimates and the errors associated with that in PP models based on remote sensing data, we determined monthly PP in the Greenland Sea according to Eppley et al. (1985), where PP is assumed to be proportional to the square root of CHL. We firstly calculated PP based on the $C_{\text {tot }}$ values from in situ profiles and used 

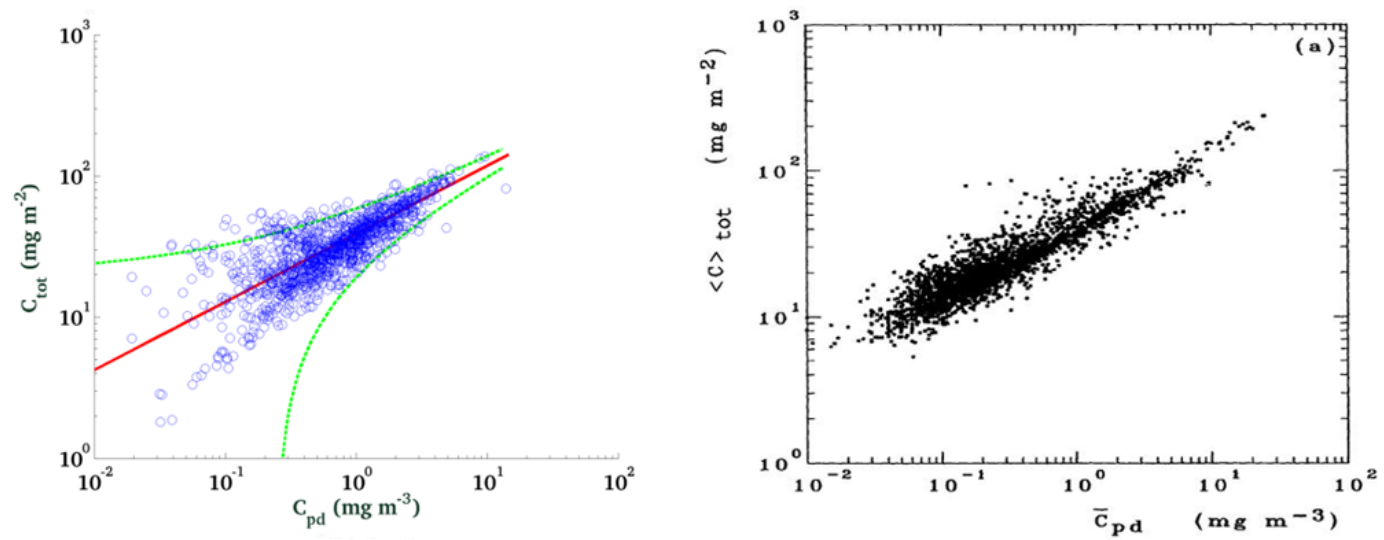

Fig. 1. Total chlorophyll content within the euphotic layer $\left(C_{\text {tot }}\right)$ versus mean chlorophyll within the surface layer $\left(C_{\mathrm{pd}}\right)$. Left: for the Greenland Sea, this study, $R=0.84, N=1199$, significant correlation $(p<0.0001)$. The red line is the regression line (Eq. 3), and green lines are the $95 \%$ confidence intervals. Right: from the global study by Morel and Berthon (1989), copyright (1989) by the Association for the Sciences of Limnology and Oceanography, Inc.

these as a reference. These reference calculations were compared to those obtained from the following: (1) Gaussians fitted to monthly in situ profiles with $0.1 \mathrm{mg} \mathrm{C} \mathrm{m}^{-3}$ step of $C_{\mathrm{pd}}$ (this study); (2) uniform profiles by keeping the surface value constant; and (3) profiles of Morel and Berthon (1989). Morel and Berthon (1989) profiles were used for $C_{\mathrm{pd}}>0.05 \mathrm{mg} \mathrm{C} \mathrm{m}^{-3}$ only to exclude the negative values which occurred for $C_{\mathrm{pd}}<0.05 \mathrm{mg} \mathrm{C} \mathrm{m}^{-3}$. For calculations of $Z_{\text {eu }}$ we used the Morel and Berthon (1989) method described in the beginning of Sect. 2.3. The errors of single profiles were calculated first, and then the monthly medians of the errors were calculated.

\section{Results}

\subsection{Data quality control and preprocessing}

Our initial CHL database for the Greenland Sea consisted of 1676 profiles, with 548 profiles derived from the unpublished database of R/V Polarstern and R/V Maria S. Merian cruises and the rest from the ARCSS-PP database. After applying quality control procedures (Sect. 2.2), 1472 profiles were left. In addition, nearly 300 profiles did not reach the euphotic depth and thus were excluded. After such preprocessing, our database consisted of 1199 profiles.

Figure 1 shows a clear relationship between $C_{\mathrm{pd}}$ (mean CHL within the penetration depth) and $C_{\text {tot }}$ (total CHL in the water column) for the Greenland Sea from our database (left) and for the global database from Morel and Berthon (1989), which is based on the analysis of 3497 profiles (right). Equations (3) and (4) correspond to the fitted regression lines of our dataset and that of Morel and Berthon (1989), respectively.

$$
C_{\text {tot }}=39.0 C_{\mathrm{pd}}^{0.48}
$$

$C_{\text {tot }}=40.6 C_{\mathrm{pd}}^{0.46}$

The slopes of the regression lines in the double-logarithmic plots are close: 0.48 for the Greenland Sea and 0.46 for the global dataset. Scatter plots show nearly no difference in the high $C_{\mathrm{pd}}$ values related to $C_{\mathrm{tot}}$. The differences between the two datasets occur at low $C_{\mathrm{pd}}$ values which for the Greenland Sea correspond to a wider range of $C_{\text {tot }}$ as compared to the global relationship. We attribute this difference to the various magnitudes of SCM in our data. Specifically, very low values of $C_{\text {tot }}$ (in the range of $1-5 \mathrm{mg} \mathrm{C} \mathrm{m}^{-2}$ ) are present in our dataset only. We have further explored the change in $C_{\text {tot }}$ with respect to $C_{\mathrm{pd}}$ variability using the heteroscedasticity test (White, 1980). The only parameter showed to be causing the change in $C_{\text {tot }}$ with respect to $C_{\mathrm{pd}}$ variability was the month (with $p=0.05$ ), supporting the choice of the categorization method by season. The other predictors tested were latitude, longitude, year, euphotic layer depth and penetration depth. For all of them the null hypothesis of heteroscedasticity was accepted at the confidence level of 0.05 . To sum up, the clear relationship between $C_{\mathrm{pd}}$ and $C_{\text {tot }}$ for the Greenland Sea proved that a mathematical dependency between these two parameters is to be expected, though it has to be regarded carefully for the low $C_{\mathrm{pd}}$ values.

\subsection{Selection of the representative surface layer chlorophyll categories and fitting of Gaussians}

Based on the histogram of $C_{\text {pd }}$ (Fig. 2), we defined six ranges of $C_{\mathrm{pd}}$ with roughly 200 profiles per range. The histogram showed that most of the profiles have low values in the upper ocean layer $\left(C_{\mathrm{pd}}\right.$ lower than $\left.1 \mathrm{mg} \mathrm{C} \mathrm{m}^{-13}\right)$. The obtained $C_{\mathrm{pd}}\left(\mathrm{mg} \mathrm{C} \mathrm{m}^{-3}\right)$ ranges were as follows: (1) $<0.3$; (2) $0.3-0.45$; (3) $0.45-0.7$; (4) $0.7-1$; (5) $1-1.5$; (6) > 1.5 . 


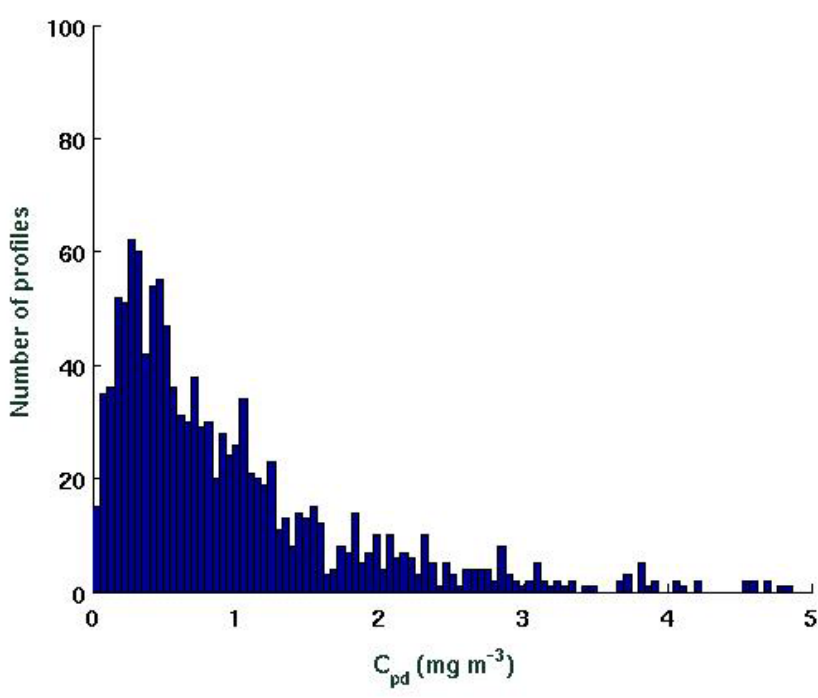

Fig. 2. Histogram describing the distribution of the mean chlorophyll within the surface layer $\left(C_{\mathrm{pd}}\right)$ over the 1199 chlorophyll profiles.

The median of the profiles for each range (see Sects. 2.32.4) showed that the shapes of the profiles for the ranges 4 to 6 are nearly identical. Therefore we combined those into one range $\left(>0.7 \mathrm{mg} \mathrm{C} \mathrm{m}^{-3}\right.$ ) that covers about 600 profiles.

Figure 3 illustrates the spatial distribution of the final four categories assigned (left), and shows the months when the samples were taken (right). South of $74^{\circ} \mathrm{N}$, in the area of the warm Atlantic waters, the category with highest surface CHL $\left(C_{\mathrm{pd}}>0.7 \mathrm{mg} \mathrm{C} \mathrm{m}^{-3}\right)$ was prevalent. In contrast, in the north-west part of the basin, which is the sea ice affected area of the Greenland shelf, the category with the lowest surface CHL $\left(C_{\mathrm{pd}}<0.3 \mathrm{mg} \mathrm{C} \mathrm{m}^{-3}\right)$ occurred more often than the other ones. Both these categories, however, appeared throughout the basin as well. The two other intermediate $C_{\mathrm{pd}}$ categories were spatially more evenly distributed. Generally, the sampling was concentrated along the two transects at $75^{\circ} \mathrm{N}$ and at $78-79^{\circ} \mathrm{N}$. Each of the two transects included samples for all the months analysed, with August being the least sampled month and April samples being more concentrated in the area north of $78^{\circ} \mathrm{N}$.

Figure 4 shows the median profiles for the four $C_{\mathrm{pd}}$ ranges. For all $C_{\mathrm{pd}}$ ranges the CHL maximum shallows towards the end of the season. The SCM for the majority of the months is most pronounced in the lowest $C_{\mathrm{pd}}$ range (plot I), where it is also deeper than in other ranges. Within this range, the magnitude of the April-May SCM is equal to or greater than in September. May to July, having no clear SCM, represents a transitional state between the two seasons. The relative spread of the maxima is highest in this range (Fig. 5). In the second and third $C_{\mathrm{pd}}$ ranges (plots II and III), the SCM is more difficult to distinguish (except for the August profiles), and there is a rather gradual shift of the maximum to- wards the surface from April to September. In the fourth and highest $C_{\mathrm{pd}}$ range (plot IV), the maxima mostly occur exactly at the surface. This is the only range with most months reaching maximum values at the surface. The fourth range shows a clear decrease of the surface CHL values from April to September.

Fitting Gaussian functions to the median profiles resulted in much smoother curves which have a single pronounced maximum (see Appendix, Fig. A2). Some of the original median profiles (Fig. 4), which are quite different from each other, appear nearly identical in the fitted Gaussians (such as April-May of the lowest $C_{\mathrm{pd}}$ range). However, the main features of the median profiles (such as the propagation of the maximum towards the surface as the season goes by in September) are also present in the fitted curves. The table with the coefficients $A, \sigma$ and $\mu$ for the Eq. (5) of the Gaussians fitted with $0.1 \mathrm{mg} \mathrm{C} \mathrm{m}^{-3}$ surface CHL resolution is given in the Appendix.

$\mathrm{CHL}=A e^{-\frac{(z-\mu)^{2}}{2 \sigma^{2}}}$

\subsection{Statistical analysis}

In addition to the figures presented above, Table 1 gives more details on the basic statistics and CHL maximum characteristics of the dataset and enables the comparison of the features of the different $C_{\mathrm{pd}}$ ranges (vertically) and of the different months (horizontally). The median, mean, inter-quartile range and standard deviation are averaged for the whole water column.

The profiles with low CHL concentration in the surface layer, the lower $C_{\mathrm{pd}}$ ranges, always show a SCM (see the depth of the CHL maximum for the first two ranges). Median values rise towards the maximum $C_{\mathrm{pd}}$, pointing out that the SCM does not critically influence the median CHL in the water column. In case of low surface concentration, however, the relative contribution of SCM to the total CHL is important, with its magnitude exceeding the surface value by up to a factor of three (e.g. see April for the lowest $C_{\mathrm{pd}}$ range). The latter is additionally supported by the months with highest CHL maximum to $C_{\mathrm{pd}}$ ratio being also those with highest $C_{\text {tot }}$ values within the range (April and May of the first range, and April and August of the second range). Median and mean for all the $C_{\mathrm{pd}}$ ranges show the bloom weakening from April till September (see also Fig. 4, for the highest range only). The CHL maximum does not show the same clear trend, e.g. the third $C_{\mathrm{pd}}$ range with all months except August having about the same CHL maximum. Generally, the mean is higher than the median, signifying that most of the outliers are higher than the median. The percentage spread of the data (interquartile range) is usually highest in the lowest $C_{\mathrm{pd}}$ range. September is the month with the least spread. The penetration depth $\left(Z_{\mathrm{pd}}\right)$ did not vary much seasonally, but showed the expected variability between the $C_{\mathrm{pd}}$ ranges: maximum $Z_{\mathrm{pd}}$ was observed in April in the lowest 

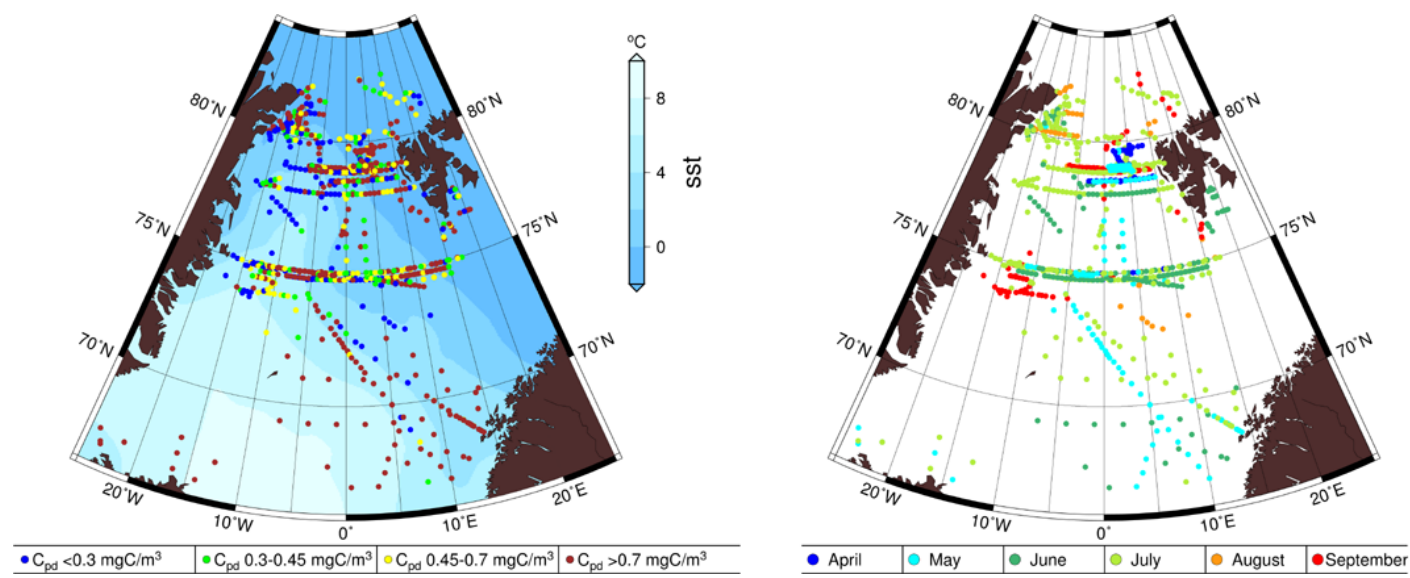

Fig. 3. Left: locations of CHL profiles, colour of the circle indicates the $C_{\mathrm{pd}}$ category assigned. In the background is the sea surface temperature climatology map for 2002-2012 (data from Physical Sciences Division, Earth System Research Laboratory, NOAA, Boulder, Colorado, http://www.esrl.noaa.gov/psd/). Right: locations of CHL profiles, colour of the circle indicates the month of sampling.

$C_{\mathrm{pd}}$ range, and minimum $Z_{\mathrm{pd}}$ was observed in April-May in the highest $C_{\mathrm{pd}}$ range. The relationship between $Z_{\mathrm{pd}}$ and $C_{\mathrm{pd}}$ (Appendix, Fig. A3) has large scatter in the low $C_{\mathrm{pd}}$ area, but overall shows significant correlation as was also the case for $C_{\text {tot }}$ (Fig. 1).

\subsection{Analysis of the seasonal variability}

Overall monthly CHL profiles of the Greenland Sea phytoplankton computed regardless of surface concentration categorization (Fig. 6, left) show a pattern similar to the median profiles of the $C_{\mathrm{pd}}>0.7 \mathrm{mg} \mathrm{C} \mathrm{m}^{-3}$ category (Fig. 4 , plot IV). Surface CHL values are highest in April, lower in May-June, and the lowest in July-August. July and August are the months with localized and clear SCM. We do not observe here the SCM in the other months as it had a variable depth and was smoothed out when averaging all categories of profiles. The depth, down to which CHL stays close to or higher than the surface value, shallows as the season goes by. As was also seen earlier in Fig. 4, the significant CHL values at depth are usually a continuation of a surface bloom in case of high surface CHL, or are a SCM in case of low surface CHL. For the smaller highly sampled HAUSGARTEN region, the stepwise decrease of surface CHL from April to September is less clear (Fig. 6, right). The peak of surface CHL occurs in April as for the whole Greenland Sea, but later in the season, the surface CHL values are alike for all the months. A SCM is seen in May-July. In August too few profiles (less than 20) were available and therefore are not compared with other months. For this small region, even though it is the most sampled region in our dataset, the spread between years in the samples of certain months is bigger than in the case of averages for the whole Greenland Sea, making the seasonal patterns observed in the small region less reliable. Hence for the further discussion we assume the averages for the whole region as the Greenland Sea phytoplankton seasonal cycle.

\subsection{Error analysis and reference to uncertainties in primary production estimates}

The error analysis, performed for the Gaussian curves retrieved here, and alternatively for the uniform profiles and those of Morel and Berthon (1989), revealed the following patterns. Compared to the uniform profiles or profiles calculated by Morel and Berthon (1989), the errors in $C_{\text {tot }}$ and $\mathrm{PP}_{\text {tot }}$ (primary production integrated for the water column) are smallest or comparable for most months at all $C_{\mathrm{pd}}$ ranges when it is the Gaussian profile that is used (see Table 2). Generally, Gaussian profiles tend to underestimate the $C_{\text {tot }}$ by $0-7 \%$ (with a relative error range from $-17 \%$ to $+6 \%$ for $C_{\text {tot }}$, and $-9 \%$ to $+3 \%$ for $\left.\mathrm{PP}_{\text {tot }}\right)$. Morel and Berthon (1989) profiles, on the contrary, always overestimate the in situ values in the case of the averages for all the months. The monthly errors for Morel and Berthon (1989) range from $-21 \%$ to $+48 \%$ for $C_{\text {tot }}$, and -11 to $+21 \%$ for $\mathrm{PP}_{\text {tot }}$. For Morel and Berthon (1989) profiles, months April and June are usually the months with the lowest errors. Errors for using uniform profiles were relatively large and ranged from $-37 \%$ to $+27 \%$ for $C_{\text {tot }}$, and $-21 \%$ to $+13 \%$ for $\mathrm{PP}_{\text {tot }}$.

In the following we discuss $C_{\text {tot }}$ and $\mathrm{PP}_{\text {tot }}$ estimates of the $C_{\text {pd }}$ category with the maximum ratio of SCM relative to surface CHL $\left(C_{\mathrm{pd}}<0.3 \mathrm{mg} \mathrm{C} \mathrm{m}^{-3}\right)$, because these are the cases of $C_{\text {tot }}$ being mostly influenced by the shape of the profile. For this range with most pronounced SCM, monthly $C_{\text {tot }}$ values from uniform CHL profiles underestimated on average by $19 \%$ the $C_{\text {tot }}$ values obtained from in situ CHL profiles. Such underestimation decreased to $6 \%$ when the Gaussian fits were used. The use of Morel and Berthon (1989) approximation resulted in an average error of $8 \%$, which is small as well, but one has to keep in mind that this is because the 

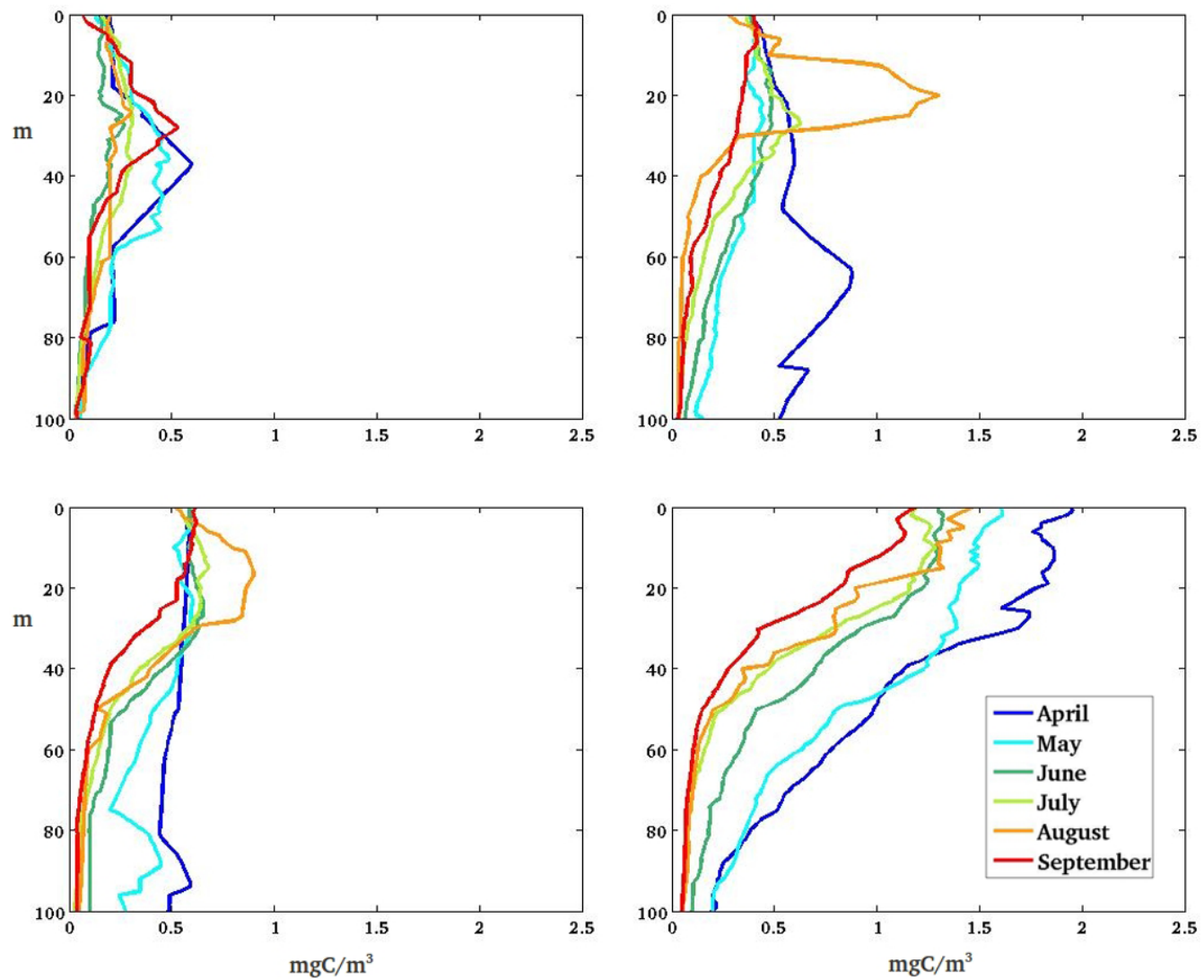

Fig. 4. Median monthly chlorophyll profiles obtained for the four ranges of mean chlorophyll within the surface layer $\left(C_{\mathrm{pd}}, \mathrm{mg} \mathrm{C}^{-3}\right)$. Ranges: (I) < 0.3; (II) 0.3-0.45; (III) 0.45-0.7; (IV) > 0.7. Data are from R/V Polarstern and Maria S. Merian cruises (unpublished), and from ARCSS-PP database, 1957-2010.

positive (up to $22 \%$ ) and negative (down to $-10 \%$ ) monthly errors cancel out each other. As expected, the errors were lower for the rough proxy of primary production, which had a monthly average underestimation of $10 \%$ when the uniform CHL profile was compared to the in situ CHL profile. The error was largest in May (-19\%) and smallest in June $(-1 \%)$. Using Gaussian profiles reduced the average error to $-3 \%$, with a small range of monthly errors (from $-7 \%$ till $1 \%)$.

Our interpretation of the differences observed is as follows. Uniform profiles are not able to represent the vertical changes of the profile and therefore result in both average underestimations ( $-19 \%$, lowest $C_{\mathrm{pd}}$ range) and overestimations (7\%, highest $C_{\mathrm{pd}}$ range) of $C_{\mathrm{tot}}$. The Morel and Berthon (1989) maximum covers a larger part of the water column, which results in a higher value than the localized maximum of the in situ profiles. Thus the in situ $C_{\text {tot }}$ is overestimated (on average 14\%). The derived Gaussian approximations have a lower magnitude of the CHL maximum than the in situ profiles, and do not reproduce the small-scale changes of the in situ CHL profile, thus typically slightly underestimating $C_{\text {tot }}$ (on average $4 \%$ ).

\subsection{Summary of the results}

In summary, the general patterns of the median profiles are the following: (1) low surface values are usually an indication of SCM; (2) the relative contribution of SCM to the total CHL in case of low surface concentration can be important, with maximum values exceeding surface CHL by up to a factor of three; (3) for the low surface CHL, total CHL is the highest in cases of pronounced SCM; (4) the relative spread of the data (interquartile range) is highest for the lowest surface concentration; (5) maxima of the profiles gradually moved from greater depths in spring towards the surface in September; (6) median values averaged for the whole water column show a weakening of the bloom from April to September; the CHL maximum values do not show such a trend; (7) when all the surface CHL concentrations are averaged for each month only, surface CHL values decrease from April to September; (8) Gaussians fitted to the median profiles generally reproduce the magnitude and position of the CHL maximum, resulting in $4 \%$ average underestimation of $C_{\mathrm{tot}}$; (9) omission of SCM in primary production models (i.e., when the uniform CHL profile is used) results in an average of about $10 \%$ underestimation for the Greenland Sea 
Table 2. Relative errors in the total $\mathrm{PP}$ and $\mathrm{CHL}$ content in the water column ( $\mathrm{PP}$ tot and $C_{\text {tot }}$ respectively). $\mathrm{PP}_{\text {tot }}$ and $C_{\text {tot }}$ inferred from in situ CHL profiles are used as a reference, and are compared to $C_{\text {tot }}$ and $\mathrm{PP}_{\text {tot }}$ inferred using (1) mathematical Gaussian fits of this study; (2) uniform CHL profiles; and (3) Morel and Berthon (1989) profiles. $C_{\text {tot }}$ and $\mathrm{PP}_{\text {tot }}$ are integrated until the euphotic depth estimated following Morel (1988). PP is proportional to square root of CHL following Eppley et al. (1985). Overestimations of the in situ values are in bold and underestimations in italic. Roman numbers indicate the four ranges of $C_{\mathrm{pd}}\left(\mathrm{mg} \mathrm{C} \mathrm{m}^{-3}\right)$ : (I) $<0.3$; (II) $0.3-0.45$; (III) $0.45-0.7$; (IV) $>0.7$.

\begin{tabular}{|c|c|c|c|c|c|c|c|c|c|}
\hline Range & Error $(\%)$ in & CHL profile used & Apr & May & Jun & Jul & Aug & Sep & Average \\
\hline \multirow{6}{*}{ I } & \multirow{3}{*}{$\mathrm{PP}_{\text {tot }}$} & Gaussian & -1 & -5 & -7 & -1 & 1 & -6 & -3 \\
\hline & & uniform & -12 & -21 & -1 & -9 & -11 & -9 & -10 \\
\hline & & M\&B 1989 & -3 & -5 & 7 & 10 & 11 & 3 & 4 \\
\hline & \multirow{3}{*}{$C_{\mathrm{tot}}$} & Gaussian & -2 & -9 & -13 & -2 & 1 & -13 & -6 \\
\hline & & uniform & -22 & -37 & -3 & -16 & -21 & -17 & -19 \\
\hline & & M\&B 1989 & -6 & -10 & 17 & 20 & 22 & 7 & 8 \\
\hline \multirow{6}{*}{ II } & \multirow{3}{*}{$\mathrm{PP}_{\text {tot }}$} & Gaussian & -3 & 3 & -1 & 0 & -9 & -1 & -2 \\
\hline & & uniform & -6 & -1 & -3 & -4 & -19 & 9 & -4 \\
\hline & & M\&B 1989 & 2 & 8 & 5 & 5 & -11 & 18 & 4 \\
\hline & \multirow{3}{*}{$C_{\text {tot }}$} & Gaussian & -5 & 6 & -2 & -1 & -17 & -2 & -3 \\
\hline & & uniform & -11 & -1 & -6 & -7 & -34 & 20 & -7 \\
\hline & & M\&B 1989 & 4 & 16 & 10 & 9 & -21 & 39 & 10 \\
\hline \multirow{6}{*}{ III } & \multirow{3}{*}{$\mathrm{PP}_{\text {tot }}$} & Gaussian & 2 & -1 & -3 & 1 & -1 & 1 & 0 \\
\hline & & uniform & 0 & -1 & 0 & 2 & -4 & 12 & 1 \\
\hline & & M\&B 1989 & 8 & 7 & 9 & 10 & 3 & 21 & 10 \\
\hline & \multirow{3}{*}{$C_{\mathrm{tot}}$} & Gaussian & 4 & -2 & -5 & 3 & -2 & 1 & 0 \\
\hline & & uniform & 0 & -3 & 0 & 4 & -8 & 24 & 3 \\
\hline & & M\&B 1989 & 17 & 15 & 18 & 20 & 7 & 48 & 21 \\
\hline \multirow{6}{*}{ IV } & \multirow{3}{*}{$\mathrm{PP}_{\text {tot }}$} & Gaussian & -3 & -2 & -3 & -2 & -5 & -4 & -3 \\
\hline & & uniform & -1 & -1 & 0 & 2 & 7 & 13 & 3 \\
\hline & & M\&B 1989 & 2 & 1 & 4 & 5 & 9 & 15 & 6 \\
\hline & \multirow{3}{*}{$C_{\mathrm{tot}}$} & Gaussian & -6 & -5 & -7 & -4 & -9 & -8 & -7 \\
\hline & & uniform & -1 & -3 & 1 & 4 & 14 & 27 & 7 \\
\hline & & M\&B 1989 & 4 & 3 & 8 & 11 & 19 & 33 & 13 \\
\hline
\end{tabular}

$\mathrm{PP}_{\text {tot }}$ at lowest surface CHL concentrations; and use of Gaussian profiles reduces the underestimation to $3 \%$.

\section{Discussion}

In the following, the specifics of Greenland Sea CHL profiles and $C_{\text {tot }}$ and their comparison to the global approximation by Morel and Berthon (1989) are further discussed with respect to the specific hydrographic conditions and other studies focusing on phytoplankton dynamics in the Arctic region (Sects. 4.1 and 4.2, respectively).

\subsection{Special features of the Greenland Sea chlorophyll profiles}

For the surface CHL lower than $1 \mathrm{mg} \mathrm{C} \mathrm{m}^{-3}$, the amount of total phytoplankton varies much more in the Greenland Sea than for the global case. The prediction of Greenland Sea $C_{\text {tot }}$ values corresponding to low $C_{\mathrm{pd}}$ is thus more challenging than that of the lower latitudes. As is the case for most Arctic waters, the ice-affected western part of the Greenland
Sea has pronounced water column stratification by salinity. The stratification here is influenced by the melting sea ice moving through the Fram Strait as it is the major gateway for the sea ice to leave the Arctic Ocean. The amount of drifting sea ice varies throughout the year and so as well does the strength of the stratification. Nutrient supply to the ocean surface layer (critical for phytoplankton growth) depends on the stratification and therefore also varies with season. At the same time a contrasting oceanographic regime with dominant thermal stratification characterizes the central basin of the Greenland Sea away from the seasonal ice zone and East Greenland Current. Thus the depth and the magnitude of the phytoplankton maximum are highly variable throughout the Greenland Sea, explaining the big range of $C_{\text {tot }}$ values corresponding to low surface CHL.

We observed two different scenarios of phytoplankton distribution in the water column and throughout the season, depending on whether the CHL of the surface layer is higher or lower than $0.7 \mathrm{mg} \mathrm{C} \mathrm{m}^{-3}$. At low surface concentration a SCM was always observed (its magnitude, however, for some profiles is quite small). This case could be typical for 

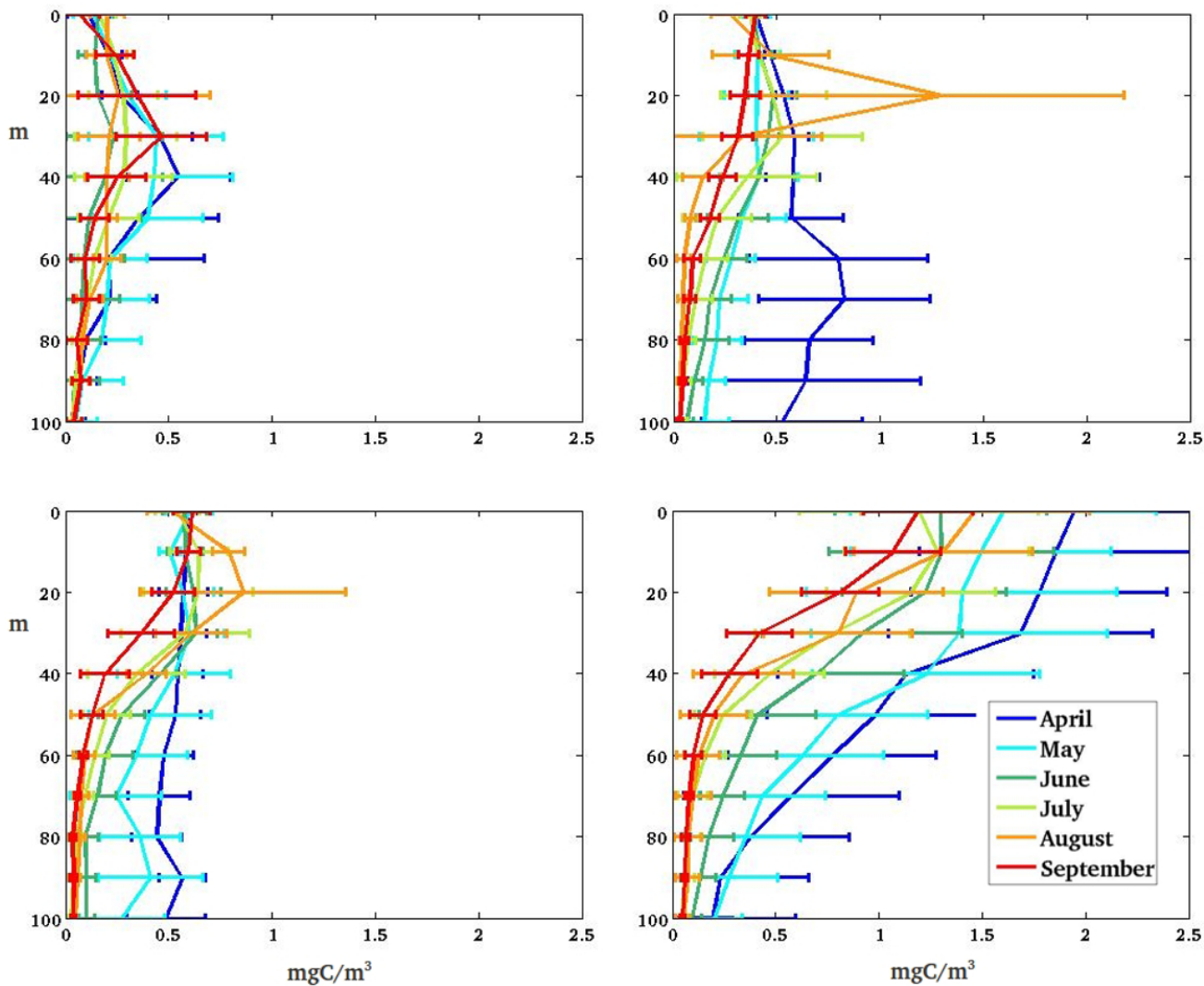

Fig. 5. Interquartile ranges for the monthly chlorophyll profiles in the four ranges of mean chlorophyll within the surface layer $\left(C_{\mathrm{pd}}\right.$, $\mathrm{mg} \mathrm{C} \mathrm{m}^{-3}$ ) binned into $10 \mathrm{~m}$ depth intervals. Ranges: (I) $<0.3$; (II) $0.3-0.45$; (III) $0.45-0.7$; (IV) $>0.7$. Data are from R/Vs Polarstern and Maria S. Merian cruises (unpublished), and from ARCSS-PP database, 1957-2010.
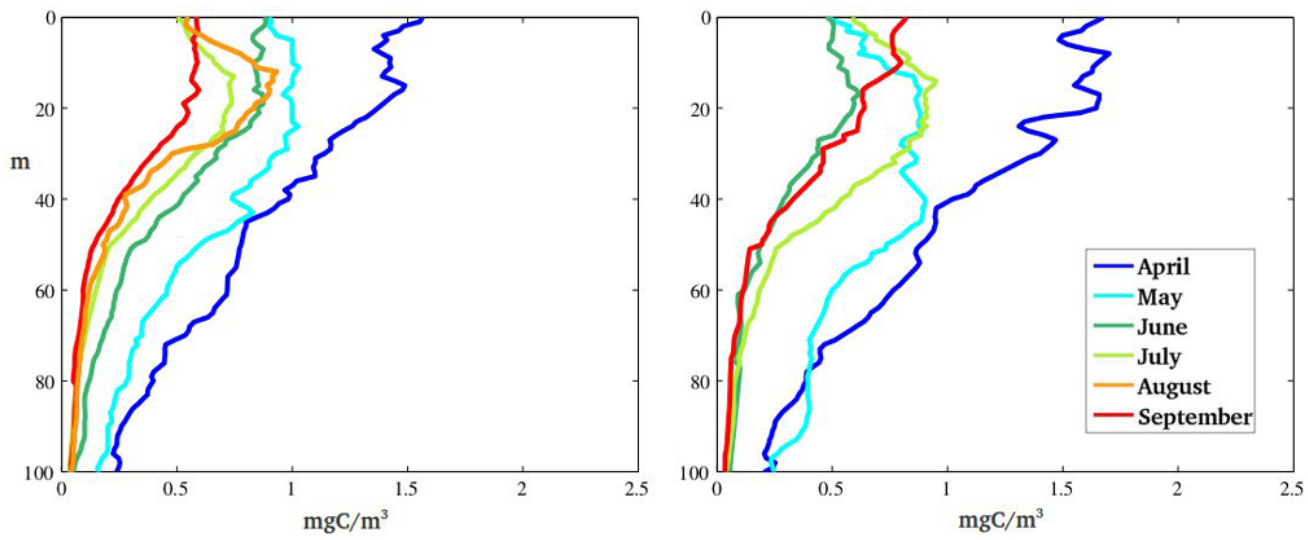

Fig. 6. Monthly CHL profiles averaged over all the $C_{\text {pd }}$ categories. Left: for the Greenland Sea (north of $66^{\circ} 33^{\prime} 39^{\prime \prime} \mathrm{N}, 45^{\circ} \mathrm{W}-20^{\circ} \mathrm{E}$ ). Right: for the smaller highly sampled region at Fram Strait only $\left(77-82^{\circ} \mathrm{N}, 5^{\circ} \mathrm{W}-10^{\circ} \mathrm{E}\right)$. At Fram Strait in August only too few profiles (less than 20) were available and therefore are not compared with other months. Data are from R/V Polarstern and Maria S. Merian cruises (unpublished), and from ARCSS-PP database, 1957-2010.

regions of sea ice melting in the Greenland Sea characterized by strong stratification and therefore lack of nutrients in the surface layer. We observed indeed that samples of low $C_{\mathrm{pd}}\left(<0.3 \mathrm{mg} \mathrm{C} \mathrm{m}^{-3}\right)$ are concentrated in the sea ice affected region, the shelf of Greenland, though they appear in other parts of the basin as well. Surface layer concentrations higher than $0.7 \mathrm{mg} \mathrm{C} \mathrm{m}^{-3}$ have a maximum CHL in the surface layer, with a gradual decrease of this maximum 


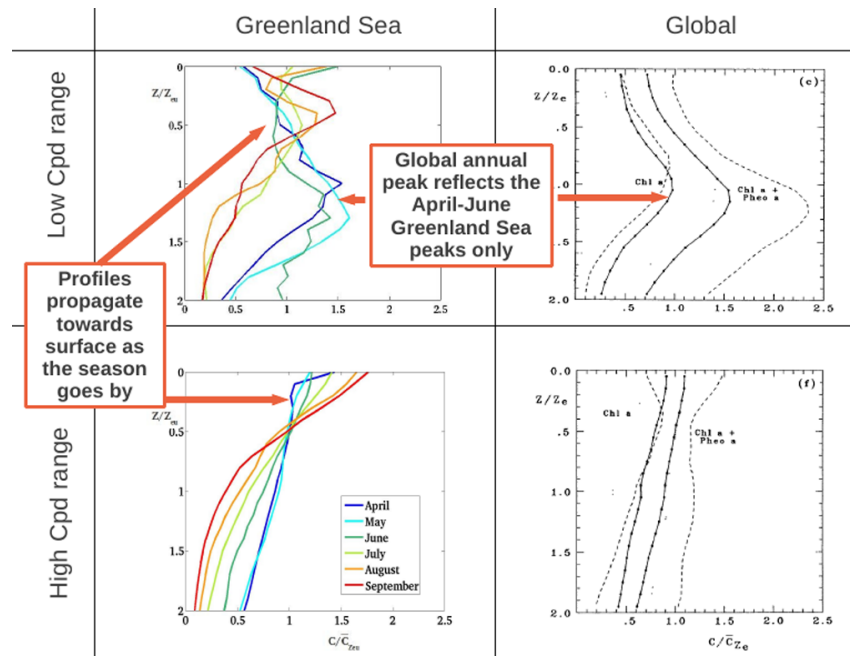

Fig. 7. Dimensionless chlorophyll profiles categorized according to their chlorophyll within the surface layer $\left(C_{\mathrm{pd}}\right)$. Two $C_{\mathrm{pd}}$ ranges out of seven computed are shown. Vertical axis shows depth divided by the euphotic layer depth $\left(Z_{\text {eu }}\right)$. Horizontal axis shows chlorophyll divided by the mean chlorophyll for $Z_{\mathrm{eu}}$. Left: Greenland Sea monthly mean profiles computed in this study. Right: from global relationship (Morel and Berthon (1989), copyright (1989) by the Association for the Sciences of Limnology and Oceanography, Inc.), we are interested in the solid line marked CHL $a$ (mean chlorophyll profile). Top is low $C_{\mathrm{pd}}$ range $\left(0.15<C_{\mathrm{pd}}<0.30\right)$; bottom is high $C_{\mathrm{pd}}$ range $\left(1.5<C_{\mathrm{pd}}<5\right)$.

from April towards September. This category was prevalent in the area south to $74^{\circ} \mathrm{N}$, which is the warm Atlantic waters area. When the whole database was categorized only by month, the seasonal cycle showed a similar pattern with a gradual decrease of surface CHL from April onwards. The depths where high CHL concentrations occur became shallower from month to month. Such a decrease of the bloom could be caused by either the phytoplankton using up the nutrients or the grazing pressure becoming stronger. We do not observe a bloom limitation by light, keeping in mind that the daylight at these latitudes is increasing from April to June (while we observed a bloom decrease for these months). As mentioned earlier, the Greenland Sea is an inhomogeneous region in terms of water mass properties. It has parts with cold and fresh waters as well as warmer and salty ones, and the sea ice drift adds to the complexity of the region. As a result, here in the same month in the top layer, both small phytoplankton concentrations and blooms are observed.

Considering the seasonal cycle, both previous satellite (Arrigo et al., 2011) and in situ (Rey et al., 2000) data analyses show that blooms start with the increase of daylight in spring and peak in May-June, with a rapid decrease afterwards. Compared to that, blooms in our analysis appear earlier, in April. The sampling period of Rey et al. (2000), however, is quite different to that of our database. Rey et al. (2000) sampled in the months May-July only in 1993-1995, while most of data used here were sampled after 1995 and for all months between April and September. Satellite-based work by Arrigo et al. (2011), also showing the May-June peak, dealt with the net primary production only. This can be quite different from the CHL values, because the higher contribution of light in May as opposed to April affects primary production more than CHL. There is yet another point of view on the North Atlantic phytoplankton seasonal cycle. Recent work by Behrenfeld (2010) shows that the bloom initiation occurs in winter when the mixed layer depth is at maximum. This is in line with what we observed in April, being the maximum of the bloom which starts to decrease afterwards. However, note that the majority of our April profiles are concentrated in the Fram Strait area $\left(78-80^{\circ} \mathrm{N}\right)$, significantly farther north than the Behrenfeld (2010) study area $\left(40-65^{\circ} \mathrm{N}\right)$.

Within our study, the SCM only contributes significantly to $C_{\text {tot }}$ within the lowest surface $\mathrm{CHL}$ range $\left(<0.3 \mathrm{mg} \mathrm{C} \mathrm{m}^{-3}\right)$. The relative spread of the data is greatest for this range, showing a highly variable position and magnitude of SCM, which is most probably caused by differences in the nutrient conditions. This variability, leading to significant relative errors in $C_{\text {tot }}$ when the modelled CHL profiles are validated by in situ CHL profiles (on average $-19 \%$ to $8 \%$ depending on the parameterization method; see Sect. 3.5 and Table 2), results in small absolute errors as compared to other ranges. Nevertheless, for the areas of the Arctic where the low $C_{\mathrm{pd}}$ profiles are prevalent, such errors associated with SCM could have a strong effect on the regional estimates of $C_{\text {tot }}$ and $\mathrm{PP}_{\text {tot }}$. In accord with a study by Tremblay et al. (2012) based on in situ data of the Canadian Arctic, we observed that the SCM is a long-lived (present from April till September) and wide-spread biological structure, which needs to be monitored carefully. In the future, freshening of the Arctic waters caused by the increasing sea ice melt due to climate change, coupled with the atmospheric circulation patterns that favour advection of the sea ice out of the Arctic Ocean (Rigor and Wallace, 2004; Liu et al., 2007; Maslanik et al., 2007), should lead to stronger water stratification. Thus the cases of low surface CHL with SCM may become even more frequent, because the nutrients will not reach the top layer.

\subsection{Comparison of the Greenland Sea chlorophyll profiles with those of the global ocean}

To compare our results to the global relationship by Morel and Berthon (1989), we derived dimensionless profiles from the data. The mean profiles for the selected low $\left(0.15<C_{\mathrm{pd}}<0.3\right)$ and high $\left(1.5<C_{\mathrm{pd}}<5\right)$ ranges introduced by Morel and Berthon (1989) are presented in Fig. 7. The examples for these two ranges are shown as they clearly present two different trophic situations. The other ranges are variations of the two mentioned above, for the Greenland Sea generally showing two different patterns of the CHL profile for April-June and August-September, and the 
spread of both depth and value of CHL maxima decreasing as the $C_{\mathrm{pd}}$ range rises. July is the "deviating" profile, in some ranges behaving like April-June, and in others like August-September.

One has to keep in mind that dimensionless profiles magnify the shape of the actual profile, giving the largest values to the steepest changes of the profile. (Therefore the CHL maximum values in Fig. 7 are not comparable with those of the median profiles in Figs. 4-6.) In the low range, the Greenland Sea April-June CHL maxima correspond to the global annual maximum. Later in the season, in July-August, the SCM value almost matches that of the global relationship, but the location is much shallower. In the high range as well, the April-June CHL maxima are like the global maximum, while in the later months both values and the depth of the Greenland Sea CHL maxima are not represented by the global relationship. This is in line with the results of the error analysis (Sect. 3.5). To sum up, although the Morel and Berthon (1989) relationships are global and exclude all the high latitudes (thus did not account for any data of the Greenland Sea) and in addition did not account for the seasonality, they agree well with the Greenland Sea CHL maxima early in the season, whereas the months after June are not correctly represented. Our results show that, for the correct parameterization of CHL content in the water column at high latitudes, we need both the monthly and surface chlorophyll-resolved relationship. A remarkable feature of our dimensionless profiles is the intersection at one depth of all the monthly profiles. It is especially visible around depths 0.5 in the high $C_{\mathrm{pd}}$ range (Fig. 7, bottom left), but was observed for all the ranges. As mentioned above the dimensionless profiles give the attention to the shape of the CHL maxima, but do not reproduce the magnitude of the CHL maxima correctly, which made us decide for the profiles having "natural" dimensions as the output of the current effort.

Comiso (2010) found small inter-annual variability of the CHL in the Greenland Sea, and Pabi et al. (2008) observed that the Greenland sector (geographically the same as our area of investigation) had the lowest inter-annual variability of primary production of all the Arctic Ocean. Small interannual variability implies that the relationship we observed may be used for any year with a minimum risk of year-toyear change.

\section{Conclusion}

In this study we derived the relationship between the CHL in the surface layer and its vertical profile for the Greenland Sea. Median profiles and the Gaussian fits to the median profiles which reduce the computational effort were obtained. The relationship is resolved in terms of CHL content in the surface layer as well as in terms of seasonal cycle.

As in the global study by Morel and Berthon (1989), we observed principally different patterns of CHL profile for low and high CHL concentration in the surface layer, which showed the need to account for the surface value when calculating the shape of the profile. Since the Morel and Berthon (1989) relationship is seasonally averaged, it captured only the early months of the Greenland Sea season, suggesting the need to use the monthly resolved relationship for the region. The dimensionless profiles of all specific surface layer CHL ranges showed a point of intersection between all monthly profiles. The monthly averaged median CHL profiles showed a clear seasonal pattern with surface CHL values decreasing and the CHL maxima becoming more localized in the water column from April till September.

The histogram of $C_{\mathrm{pd}}$ (CHL in the surface layer) revealed the majority of profiles having low CHL values in the surface layer. We have also observed that in the Greenland Sea low surface $\mathrm{CHL}$ values correspond to a larger range of total CHL than globally (Fig. 1), which explains that here the estimation of total CHL from $C_{\mathrm{pd}}$ is less reliable. The reason is the variable values and position of a subsurface chlorophyll maximum, which had a significant value when related to $C_{\mathrm{pd}}$ for the profiles with low surface CHL. The error analysis for profiles with low surface CHL $\left(C_{\mathrm{pd}}<0.3 \mathrm{mg} \mathrm{C} \mathrm{m}^{-3}\right)$ showed that the use of the Gaussian parameterization instead of the uniform CHL profile reduced the underestimation of total CHL on average from $19 \%$ to $6 \%$. At the same time, errors in rough estimates of primary production decreased on average from $10 \%$ to $3 \%$. The simple primary production model used here (Eppley et al., 1985) has a number of limitations, but proved to estimate consistent global and regional average production (Carr et al., 2006), and was easy to implement. For all the surface CHL concentrations, Gaussian approximations derived here on average underestimate the in situ $C_{\text {tot }}$ value by $4 \%$, which is an improvement as compared to values obtained from Morel and Berthon (1989) profiles (14\% overestimation), or uniform profiles (from $19 \%$ underestimation to $7 \%$ overestimation depending on the $C_{\mathrm{pd}}$ range). The mathematical fits of this study can be used to obtain the CHL profile based on the satellite CHL value (which well coincides with the $C_{\mathrm{pd}}$ value). This CHL profile is in turn meant as an input to a primary production model for improving the primary production estimates in the Arctic Ocean.

\section{Supplementary material related to this article is available online at: http://www.ocean-sci.net/9/431/2013/ os-9-431-2013-supplement.zip.}



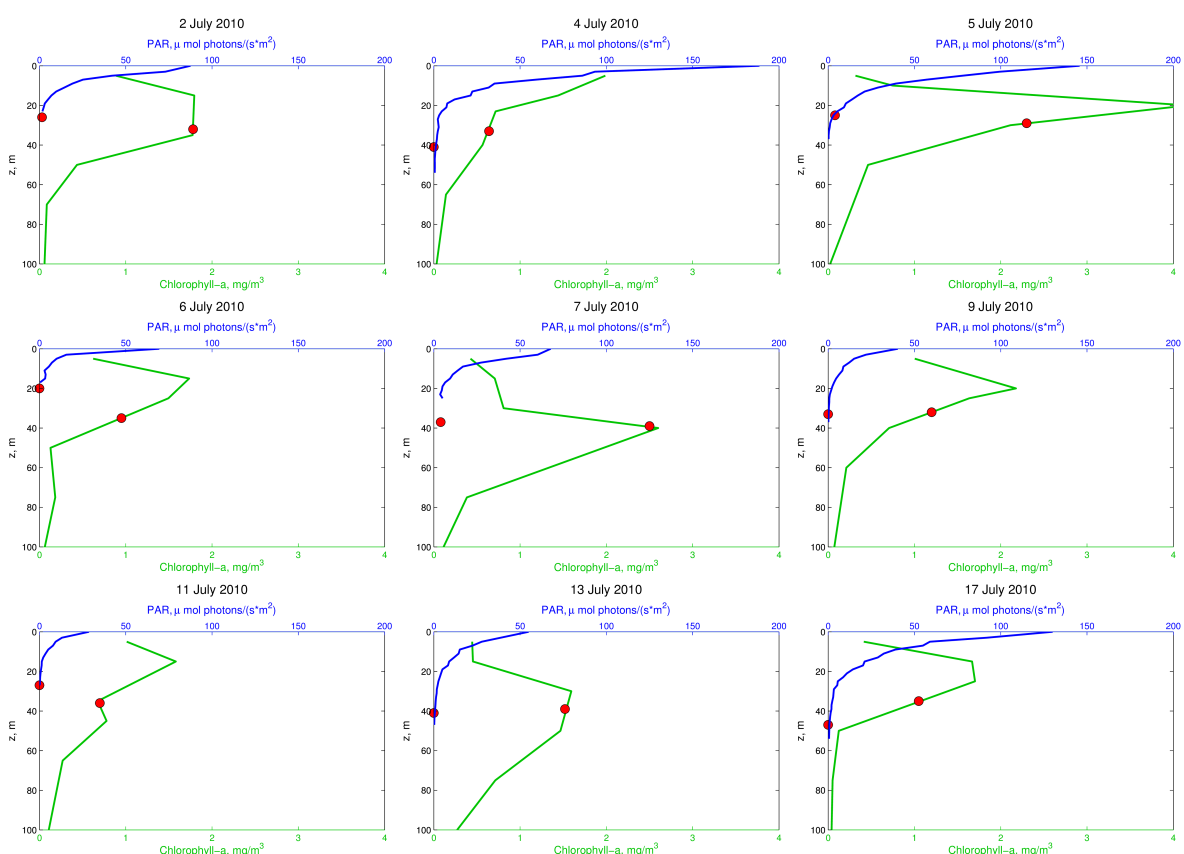

Fig. A1. Vertical profiles of PAR (photosynthetically active radiation) and CHL (chlorophyll $a$ ) simultaneously taken in Greenland Sea in July 2010. Euphotic layer depths inferred from CHL profiles following Morel (1988) and calculated from PAR profile are marked as red circles on the corresponding profiles. Average error for Morel (1988) euphotic layer depth is $23 \%$ (Sect. 2.3). Data are from R/V Polarstern cruise.
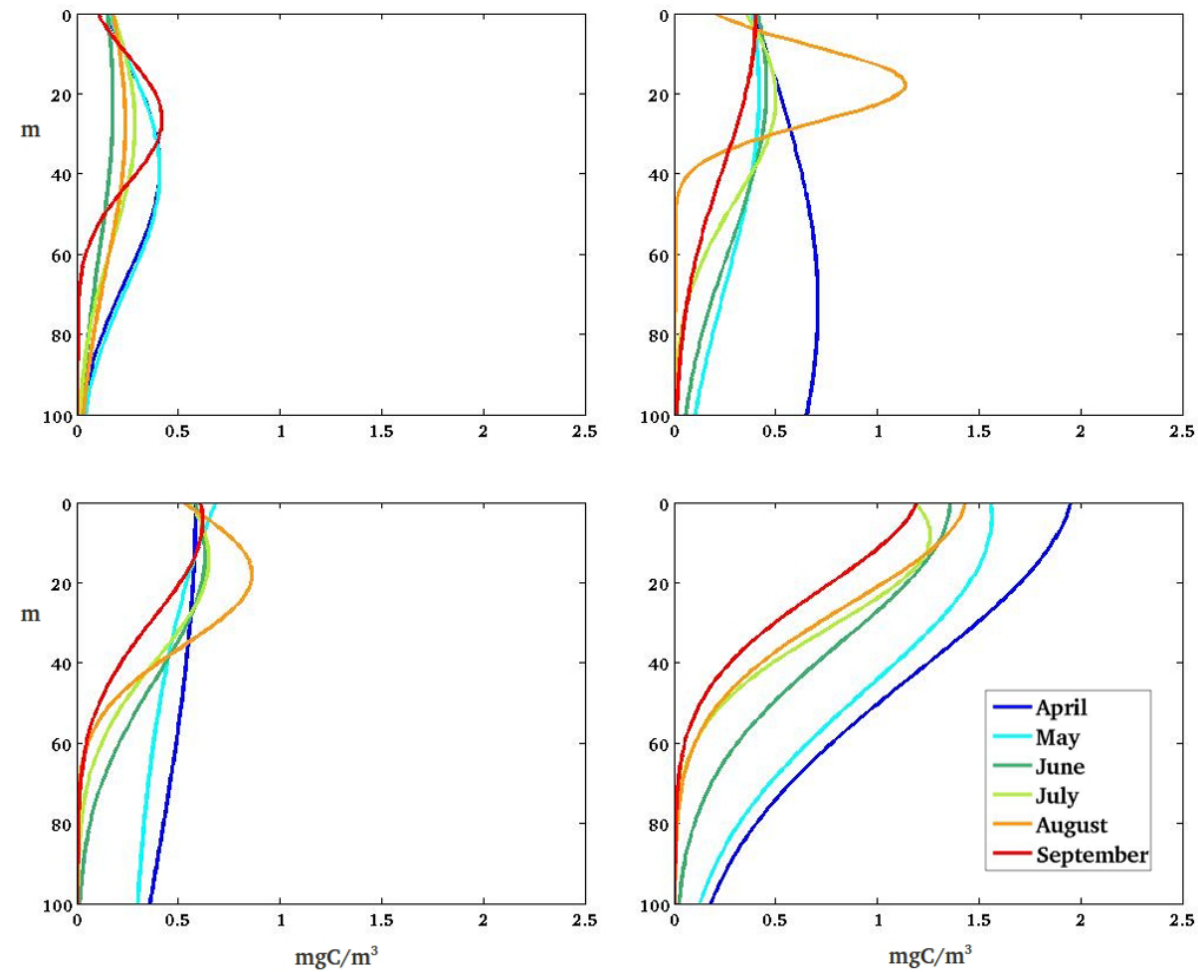

Fig. A2. Gaussians fitted to the median monthly chlorophyll profiles obtained for the four ranges of mean chlorophyll within the surface layer $\left(C_{\mathrm{pd}}, \mathrm{mg} \mathrm{C} \mathrm{m}^{-3}\right)$. Ranges: (I) < 0.3; (II) 0.3-0.45; (III) 0.45-0.7; (IV) > 0.7. Data are from R/V Polarstern and Maria $S$. Merian cruises (unpublished), and from ARCSS-PP database, 1957-2010. 


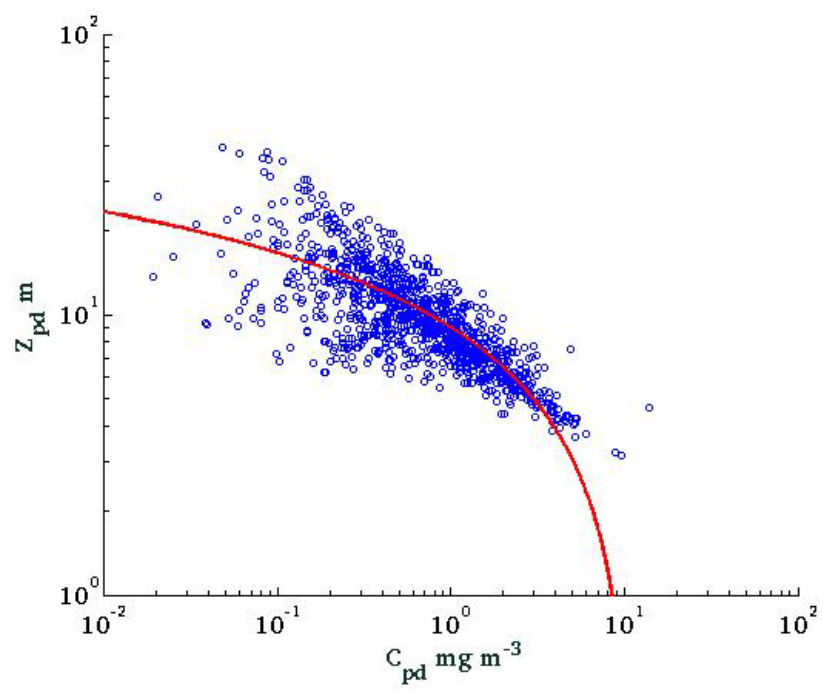

Fig. A3. Penetration depth, also called first optical depth $\left(Z_{\mathrm{pd}}\right)$, versus mean chlorophyll within the surface layer $\left(C_{\mathrm{pd}}\right) . R=0.71$, $N=1199$, significant correlation $(p<0.0001)$. Red line is the regression line.

Acknowledgements. The current work was supported by POLMAR Helmholtz Graduate School for Polar and Marine research, AWI and Helmholtz Impulse and Network Fund (HGF Young Investigators Group Phytooptics). We thank D. Antoine for helpful discussions, G. Suresh for correcting the language issues, A. Bernhardt for photosynthetically available radiance calculations, C. Lorenzen and S. Murawski for chlorophyll $a$ measurements in the laboratory, and all students and scientists who did the water filtration on board the research vessels. We are also grateful to the Anonymous Reviewer and J. Schwarz for their comments which helped to improve the manuscript.

Edited by: J. M. Huthnance

\section{References}

Antoine, D. and Morel, A.: Oceanic primary production: I. Adaptation of a spectral light-photosynthesis model in view of application to satellite chlorophyll observations, Global Biogeochem. Cy., 10, 43-55, 1996.

Antoine D., André J. M., and Morel, A.: Oceanic primary production: II. Estimation at global scale from satellite (Coastal Zone Color Scanner) chlorophyll, Global Biogeochem. Cy., 10, 57-69, 1996.

Arnone, R. A., Casey, B., Ko, D., Flynn, P., Carrolo, L., and Ladner, S.: Forecasting Coastal Optical Properties using Ocean Color and Coastal Circulation Models, Proc. Of SPIE Vol. 6680, 66800S, doi:10.1117/12.737201, 2007.

Arrigo, K. R. and van Dijken, G. L.: Secular trends in Arctic Ocean net primary production, J. Geophys. Res., 16, C09011, doi:10.1029/2011JC007151, 2011.

Arrigo, K. R., Matrai, P. A., and van Dijken, G. L.: Primary productivity in the Arctic Ocean: Impacts of complex optical properties and subsurface chlorophyll maximum on large-scale estimates, $\mathrm{J}$. Geophys. Res., 116, C11022, doi:10.1029/2011JC007273, 2011.

Behrenfeld, M. J.: Abandoning Sverdrup's Critical Depth Hypothesis on phytoplankton blooms, Ecology, 91, 977-989, 2010.

Behrenfeld M. J. and Falkowski, P. G.: Photosynthetic rates derived from satellite-based chlorophyll concentration, Limnol. Oceanogr., 42, 1-20, 1997.

Budéus, G. and Ronski, S.: An integral view of the hydrographic development in the Greenland Sea over a decade, The Open Oceanography Journal, 3, 1874-2521, doi:10.2174/1874252100903010008, hdl:10013/epic.32547, 2009.

Carr, M.-.E., Friedrichs, M. A. M.,Schmeltz, M., Aita, M. N., Antoine, D., Arrigo, K. R., Asanuma, I., Aumont, Barber, R., Behrenfeld, M., Bidigare, R., Bustenhuis, E., Campbell, J., Ciotti, A., Dierssen, H., Dowell, M., Dunne, J., Esaias, W., Gentili, B., Gregg, W.,, Groom, Hoepffner, N., Ishizaka, J., Kameda, T., LeQuere, C., Lohrenz, S., Marra, J., Melin, F., Moore, K., Morel, A., Reddy, T. E., Ryan, J., Scardi, M., Smyth, T., Turpie, K., Tilstone, G., Waters, K., and Yamanaka, Y.: A comparison of global estimates of marine primary production from ocean color, Deep Sea Res. II, 53, 741-770, doi:10.1016/j.dsr2.2006.01.028, 2006.

Comiso, J. C.: Polar oceans from space, New York, Springer, 741770, 2010.

Edler, L.: Recommendations on methods for marine biological studies in the Baltic Sea, Phytoplankton and chlorophyll, BMB Publ., 5, 1-38, 1979.

Eppley, R., Steward, E., Abbott, M., and Heyman, U.: Estimating ocean primary production from satellite chlorophyll: introduction to regional differences and statistics for the Southern California Bight, J. Plankton Res., 7, 57-70, 1985.

Evans, C. A. and O'Reily, J. E.: A handbook for the measurement of chlorophyll a in netplankton and nanoplankton, BIOMASS Handbook, 9, 1-14, 1987.

Gordon, H. R. and McCluney, W. R.: Estimation of the depth of sunlight penetration in the sea for remote sensing. Applied Optics, 14, 413-416, 1975.

Gordon, H. R. and Morel, A. Y.: Remote Assessment of Ocean Color for Interpretation of Satellite Visible Imagery: A review, Springer-Verlag. Berlin, p. 114, 1983.

Hill, V. J., Matrai, P. A., Olson, E., Suttles, S., Steele, M., Codispoti, L. A., and Zimmerman, R. C. Synthesis of integrated primary production in the Arctic Ocean: II. In situ and remotely sensed estimates, Prog. Oceanogr., 110, 107-125, doi:10.1016/j.pocean.2012.11.005, 2013.

Lee, Z., Weidemann, A., Kindle, J., Arnone, R., Carder, K. L., and Davis, C.: Euphotic zone depth: Its derivation and implication to ocean-color remote sensing, J. Geophys. Res., 112, C03009, doi:10.1029/2006JC003802, 2007.

Liu, J., Curry, J. A., Dai, R., and Horton, R.: Causes of the northern high-latitude land surface winter climate change, Geophys. Res. Lett., 34, L14702, doi:10.1029/2007GL030196, 2007.

Maslanik, J., Drobot, S., Fowler, C., Emery, W., and Barry, R.: On the Arctic climate paradox and the continuing role of atmospheric circulation in affecting sea ice conditions, Geophys. Res. Lett., 34, L03711, doi:10.1029/2006GL028269, 2007.

Matrai, P. A., Olson, E., Suttles, S., Hill, V. J., Codispoti, L. A., Light, B., and Steele, M.: Synthesis of primary production in the 
Arctic Ocean: I. Surface waters, 1954-2007, Prog. Oceanogr., 110, 93-106, , doi:10.1016/j.pocean.2012.11.004, 2013.

Matsuoka, A., Huot, Y., Shimada, K., Saitoh, S. I., and Babin, M.: Bio-optical characteristics of the western Arctic Ocean: implications for ocean color algorithms, C. J. Remote Sens., 33, 503518, 2007.

Matsuoka, A., Hill, V., Huot, Y., Bricaud, A., and Babin, M.: Seasonal variability in the light absorption properties of western Arctic waters: parameterization of the individual components of absorption for ocean color applications, J. Geophys. Res., 116, C02007, doi:10.1029/2009JC005594, 2011.

Milutinovic, S.: Uncertainty in a model for estimating euphotic depth from satellite observations of chlorophyll, NERSC Special Report, No. 88, Nansen Environmental and Remote Sensing Center, Bergen, Norway, 2011.

Morel, A.: Optical modeling of the upper ocean in relation to its biogenous matter content (case 1 waters), J. Geophys. Res., 93, 10749-10768, 1988.

Morel, A. and Berthon, J. F.: Surface Pigments, Algal Biomass Profiles, and Potential Production of the Euphotic Layer: Relationships Reinvestigated in View of Remote-Sensing Applications. Limnol. Oceanogr., 34, 1545-1562, 1989.

Morel, A. and Maritorena, S.: Bio-optical properties of oceanic waters: A reappraisal, J. Geophys. Res., 106, 7163-7180, 2001.

Pabi, S., van Dijken, G. L., and Arrigo, K. R.: Primary Production in the Arctic Ocean, 1998-2006, J. Geophys. Res., 113, C08005, doi:10.1029/2007JC004578, 2008.

Reigstad, M., Carroll, J., Slagstad, D., Ellingsen, I. H., and Wassmann, P.: Intra-regional comparison of productivity, carbon flux and ecosystem composition within the northern Barents Sea, Prog. Oceanogr., 90, 33-46, doi:10.1016/j.pocean.2011.02.005, 2011.

Rey, F., Noji, T. T., and Miller, L. A.: Seasonal phytoplankton development and new production in the central Greenland Sea, Sarsia, 85, 329-344, 2000.

Rigor, I. G. and Wallace, J. M.: Variations in the age of Arctic seaice and summer sea-ice extent, Geophys. Res. Lett., 31, L09401, doi:10.1029/2004GL019492, 2004.
Rudels, B. and Quadfaselm D. : Convection and deep water formation in the Arctic Ocean - Greenland Sea system, J. Marine Syst., 2, 435-450, 1991.

Sakshaug, E.: Primary and secondary production in the Arctic Seas, in: The Organic Carbon Cycle in the Arctic Ocean, edited by: Stein, R. and Macdonald, R., Springer, 57-81, 2004.

Schauer, U., Beszczynska-Möller, A., Walczowski, W., Fahrbach, E., Piechura, J., and Hansen, E.: Variation of Measured Heat Flow Through the Fram Strait Between 1997 and 2006, Arcticsubarctic ocean fluxes: defining the role of the northern seas in climate, edited by: Dickson, R. R., Meincke, J.. and Rhines, P. Dordrecht, Springer, 65-85, 2008.

Soltwedel, T., Bauerfeind, E., Bergmann, M., Budaeva, N., Hoste, E., Jaeckisch, N., Juterzenka, K., Matthiessen, J., Mokievsky, V., Noethig, E.-M., Queric, N., Sablotny, B., Sauter, E., Schewe, I., Urban, B., Wegner, J., Wlodarska-Kovalczuk, M., and Klages, M.: HAUSGARTEN: multidisciplinary investigations at a deepsea, long-term observatory in the Arctic Ocean, Oceanography, 18, 46-61, 2005.

Tremblay, J.-É., Raimbault, P., Martin, J., and Garcia, N.: The Ecology and Biogeochemistry of Subsurface Phytoplankton Layers in the Arctic Ocean, IPY2012 Conference - Montréal, Canada, 2227 April 2012.

Smith, R. C. and Baker, K. S.: The analysis of ocean optical data. Ocean Optics (Bellingham, Wash.), 7, 119-126, 1984.

Stramski, D., Reynolds, R. A., Babin, M., Kaczmarek, S., Lewis, M. R., Röttgers, R., Sciandra, A., Stramska, M., Twardowski, M. S., Franz, B. A., and Claustre, H.: Relationships between the surface concentration of particulate organic carbon and optical properties in the eastern South Pacific and eastern Atlantic Oceans, Biogeosciences, 5, 171-201, doi:10.5194/bg-5-171-2008, 2008.

Weston, K., Fernand, L., Mills, D. K, Delahunty, R., and Brown, J.: Primary production in the deep chlorophyll maximum of the northern North Sea, J. Plankton Res., 27, 909-922, 2005.

White, H.: A heteroskedasticity-consistent covariance matrix estimator and a direct test for heteroskedasticity, Econometrica, 48, 817-838. doi:10.2307/1912934, 1980. 